\title{
Early diagnosis of melanoma by surface microscopy (dermatoscopy)
}

\author{
Department of Dermatology, Escola Paulista de Medicina - São Paulo, Brazil
}

\begin{abstract}
The main objective of surface microscopy is the early and accurate diagnosis of melanoma in its initial phases of evolution and infiltration. Since the development of the dermatoscope in the 1990's, surface microscopy has become a simple technique. Differential diagnosis of pigmented skin lesions can be achieved with a diagnostic sensitivity of about 90 percent, and the proper differentiation of pigmented melanocytic and non-melanocytic lesions, and malignant and benign melanocytic lesions, may also be safely determined.
\end{abstract}

UNITERMS: Dermatoscopy. Melanoma. Surface Microscopy.

\section{INTRODUCTION}

The clinical evaluation of pigmented skin lesions frequently imposes difficulties on the physician (independent of specialty), mainly in the differentiation of benign and malignant pigmented lesions, and melanocytic and nonmelanocytic lesions. Clinical studies to determine the accuracy of the diagnosis, and differentiation of pigmented lesions based solely on the naked eye have demonstrated results varying from 60 to 80 percent. However, this differentiation becomes essential in establishing clinical and surgical procedures, which are different for each of the pigmented lesions.

The alarming increase in the incidence of melanoma in the last three decades has prompted the development of auxiliary diagnostic methods for the early detection and better differentiation of melanoma from other pigmented skin lesions, that may precede it. An inadequate approach to melanoma may significantly compromise the prognosis. In this context, surface

\section{Adress for correspondence: \\ Francisco Macedo Paschoal \\ Rua Cardoso de Almeida, 788 - Perdizes \\ São Paulo/SP - Brasil - CEP 05013-001}

microscopy has been distinguished as an auxiliary method for the differential diagnosis of pigmented lesions of benign, premalignant and malignant types.

In 1636, Johan Chritophorus Kolhaus recognized small vessels in the nail bed using microscopy. Later on, in 1893 Unna used oil immersion, which made the skin more transparent, to examine vulgar lupus lesions. In 1921, Johann Saphier (considered by many the father of modern surface microscopy) published four reports on the method, and was the first to use the term "dermatoscopy." GOLDMAN (1951) and MACKIE (1971) reported on the usefulness of this technique for pigmented lesions of difficult clinical differentiation. PEHAMBERGER, STEINER and WOLFF ${ }^{3}$ used a stereomicroscope to study 3,000 pigmented lesions in 1987, and established morphological criteria for each of the diseases. Due to the dimensions of the apparatus used, this method did not become popular. In 1990, the introduction of instruments similar to otoscopes, called dermatoscopes, allowed for rapid and more feasible surface microscopy. The term "dermatoscopy" has been used for such procedures ever since.

Currently, the term "epiluminescence microscopy" is accepted as a synonym of dermatoscopy.' The basic principle of this technique is to decrease light refraction by using oil immersion. Thus, light penetrates and enables 


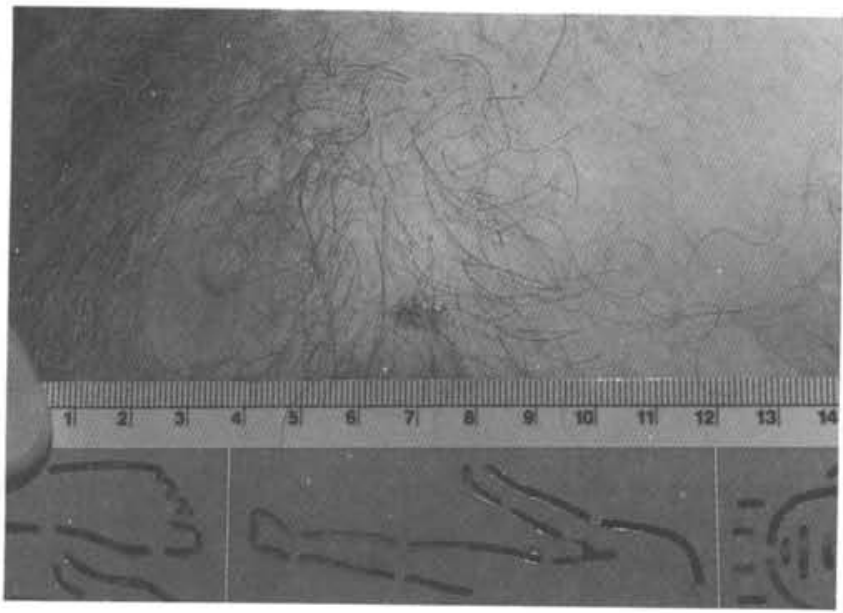

Figure 1

the study of deep skin layers, such as the dermoepidermal junction and papillary dermis, by a non-invasive method. Thus, by using the dermatoscope, we have access to various cutaneous structures not visible to the naked eye, and have opened up a new semiologic field. ${ }^{3}$

The main indication would be in the differential diagnosis of melanoma; principally of flat lesions, where it is best applied, and of lesions smaller than $6 \mathrm{~mm}$, where the $\mathrm{ABC}$ rule (asymmetry, border, color, and diameter of pigmented lesions) is usually less relaible. The proper differentiation of melanocytic and non-melanocytic pigmented lesions, and of benign and malignant melanocytic lesions, is possible when using the dermatoscope. The photographic documentation with a macro contact lens

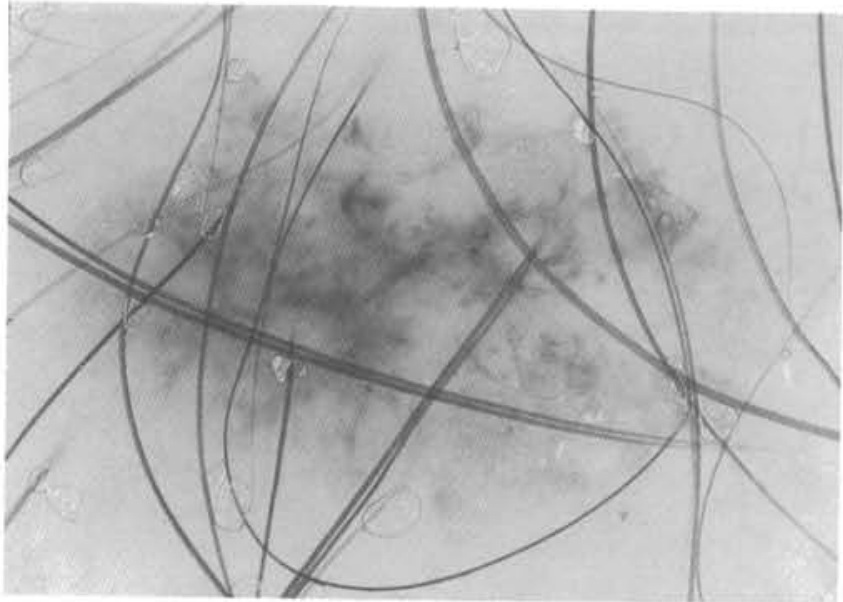

Figure 2

allows the monitoring of lesions considered to be precursors of melanoma; e.g. the atypical melanotic nevus (dysplastic nevus) and the giant congenital melanotic nevus.

Considering our personal experience and data, and the literature, ${ }^{2.4}$ it may be concluded that surface microscopy improves diagnostic sensibility from 60 to 90 percent when evaluating pigmented skin lesions. Its clinical importance is based on four main points, that it:

1. Affects future strategies for early detection of melanoma, making them more rational.

2. Minimizes unnecessary surgery.

3. Influences the choice of the appropriate surgical procedure, in accordance with the type of pigmented lesion.

4. Ascertains a diagnosis for the patient prior to biopsy.

\section{Resumo}

O objetivo maior da Microscopia de superfície é o diagnóstico precoce e correto do Melanoma nas fases iniciais de evoluçẫo e infiltraçāo. Com a introdução do Dermatoscopio na década de 1990 a Microscopia de Superficie tornou-se de fácil aplicação. Com ela é possivel proceder o diagnóstico diferencial da lesões pigmentadas cutâneas com uma acuidade diagnóstica em torno dos $90 \%$, e determinar de forma segura a diferenciação das lesões pigmentadas melanociticas e não melanociticas e das lesōes melanocíticas benignas e malignas.

\section{REFERENCES}

1. Bahmer FA, et al. Terminology In Surface Microscopy. J Am Acad Dermatol 1990;26:1159-62.

2. Kener RO, et al. Clinical diagnosis of pigmented lesions using digital epiluminescence microscopy. Arch Dermatol 1993;129:157-74.
3. Pehamberger $\mathrm{H}$, et al. In vivo epiluminescence microscopy of pigmented skin lesions. I. Pattern analysis of pigmented skin lesions. J Am Acad Dermatol 1987; 17:571-83.

4. Steiner A, et al. In vivo epiluminescence microscopy of pigmented skin lesions. II. Diagnosis of small pigmented skin lesions and early detection in malignant melanoma. J Am Acad Dermatol 1987; 17:584-91. 